\title{
Polymeric Nanoparticles in Dermocosmetic
}

\author{
Nanopartículas Poliméricas en Dermocosmética
}

\author{
Bahamonde-Norambuena, D."; Molina-Pereira, A..; Mario Cantin**; \\ Muñoz, M. ${ }^{* * *, * * * * ;}$; Katherine Zepeda ${ }^{* * * * * *} \&$ Cristian Vilos ${ }^{* * * * * *, * * * * * * * *}$
}

\begin{abstract}
BAHAMONDE-NORAMBUENA, D.; MOLINA-PEREIRA, A.; CANTIN, M.; MUÑOZ, M.; ZEPEDA, K. \& VILOS, C. Polymeric nanoparticles in dermocosmetic. Int. J. Morphol., 33(4):1563-1568, 2015.

SUMMARY: Recent advances in the fields of biomaterials and nanotechnology have allowed the development of advanced nanoparticles for biomedical applications. Despite a vast number of nanostructures such as liposomes, solid-lipid nanocapsules, polymeric and hybrid lipid-polymer nanoparticles have been studied as carriers for drug delivery for different pathologies with remarkable promising results; the use of polymeric nanoparticles in dermocosmetic still has not been widely explored. The evolution of cosmetic into the care skin and dermatology represents novel technological challenges. Also, the increasing knowledge about normal skin physiology and advances in nanotechnology provide an attractive environment for the creation of innovative dermocosmetic formulations. In this work, we discuss the state of the art of polymeric nanoparticles formulated for dermocosmetics, its mechanisms of action, and diffusion into the skin.
\end{abstract}

KEY WORDS: Nanotechnology; Polymeric nanoparticles; Cutaneous morphology; Cosmetic; Dermocosmetic.

\section{INTRODUCTION}

The applications of nanotechnology in the human health demand the use of biomaterials with biodegradability and biocompatibility properties. The attribute of biodegradability is due when the environmental conditions induce the degradation of biomaterials by biocatalysis processes (e.g. fungi, bacteria, enzymes), chemical or radical processes (e.g. hydrolysis, oxidation, UV radiation) (Guo et al., 2012; Thouand, 2014). The biocompatibility is the ability of a material to perform an appropriate host response in a particular application, that include be non-toxic, noncancerogenic, non-mutagenic, non-allergenic, free from contaminants (e.g., additives, solvents, and synthesis residues), bioresorbability, does not induce adverse immunological response, and its degradation products be also biocompatible (Kim et al., 2010; Vilos \& Velasquez, 2012).

Biodegradable and biocompatible synthetic polymers have been intensely investigated in the formulation of drug delivery systems because they provide a strong platform to prepare stable, and homogenous nanoparticles loaded with drugs that present predictable fashion release (Choi et al., 2014; Vilos et al., 2012, 2013, 2014, 2015; Cantín et al., 2013; Vilos, 2014).

Also, these polymers can be combined with other copolymers, and functionalized with targeting molecules improving the pharmacological effectiveness of the drugs (Fredman et al., 2015). On this context, the number and possibilities of multifunctional nanostructures able to create with those polymers is unprecedented (Kamaly et al., 2012; Xu et al., 2015). Another property of polymeric nanoparticles is its highly talented to penetrate biological barriers such as endothelial, tissues, and skin (Barua \& Mitragotri, 2014).

Skin represents a symbol of beauty, and the use of cosmetics to enhance personal appearance has been described since ancient civilizations. Currently, the facial aesthetic is the main reason for dermatological consultation (Freitag \& Cestari, 2007). The modern cosmetics have taken a new role

"Escuela de Tecnología Médica, Universidad Andres Bello, Facultad de Medicina, Santiago, Chile

${ }^{* *}$ CIMA Research Group, Faculty of Dentistry, CEMyQ, Universidad de La Frontera, Temuco, Chile

${ }^{* * *}$ Center of Research in Biomedical Sciences, Universidad Autónoma de Chile, Temuco, Chile

*****Fellow Research, Universidad Científica del Sur, Lima, Perú.

****** Programa de Doctorado en Farmacología, Facultad de Ciencias Químicas y Farmacéuticas, Universidad de Chile

*******C Center for Integrative Medicine and Innovative Science, Universidad Andres Bello, Facultad de Medicina, Santiago, Chile

******** Center for the Development of Nanoscience and Nanotechnology CEDENNA FB0807, Santiago, Chile 
in dermatology by ensuring care, and skin health, along with improving the appearance (Dreno et al., 2014). In this context, dermocosmetics is an emerging field that is incorporating innovative approaches based on polymeric nanoparticles and promises to introduce new paradigms in the cosmetics industry (Morganti, 2010). In this work, we discuss the state of the art of polymeric nanoparticles formulated for dermocosmetics purposes, its mechanisms of action and diffusion in the skin, and the future perspectives.

Polymeric nanostructures. Current advances in pharmaceutical technology provide support to generate nanostructures with different inner morphology able to load bioactive compounds with diverse chemical nature. Figure 1 describes the most common types of polymeric nanoparticles: nanospheres (matrix system) and nanocapsules (reservoir system). Nanospheres usually incorporate the bioactive molecule between the polymer networks, while nanocapsules typically load water dissolving the drug in the core contained in a polymeric shell (Guterres et al., 2007; Vilos \& Velasquez).

Skin. The skin has a complex morphology. The skin and its appendages (hair follicles, sweat glands, sebaceous glands, nails, and mammary glands) establish the integumentary system. Histologically, skin has two main layers-the epidermis and the dermis-with a subcutaneous fascia called the hypodermis, which lies deep in the dermis. The epidermis is formed of four to five layers of cells made mostly out of keratinocytes, along with three other different and less abundant cells; the dermis underlies the epidermis, and the hypodermis is a looser connective tissue that is located beneath the dermis (it blends to the dermis with an unclear boundary) (Arda et al., 2014).

The skin represents between $12-15 \%$ of body weight and covers a surface area of about $1.2-1.3 \mathrm{~m}^{2}$. The thickness of the skin is less than $2 \mathrm{~mm}$ and comprises of three layers: the epidermis, dermis, and hypodermis. The outer skin layer (epidermis) poses a rate-limiting barrier for diffusion and consists of keratin-filled dead cells entirely surrounded by ceramides, triglycerides, cholesterols and free fatty acids. The mechanical support of the skin is localized in the dermis and is characterized by elastin and collagen fibers. This layer also is highly vascularized and permeable to solutes, containing the sebaceous glands, hair follicles, and sweat glands (Bouwstra \& Honeywell-Nguyen, 2002).

The major challenge in topical drug delivery is across the skin (stratum corneum) because it is an efficient physical barrier. The absorption of any kind of material there can be considered two general pathways: through the stratum corneum and the underlying layers or along the skin appendages. Generally, the stratum corneum is assumed to be the main barrier for absorption, through the corneocytes or along the intercellular spaces along the lipid matrix, the latter most suited for penetration, offering channel-like structures providing higher diffusivity although the pathway is much longer (Schneider et al., 2009). The stratum corneum can be considered to be a lipoidic compartment whereas the underlying living tissue is a more aqueous environment. Hence lipophilic molecules can distribute more easily in the stratum corneum and penetration is facilitated, and the absorbent needs to fit into the intercellular space and need to move along the lipid phase or the aqueous phase, respectively, restricting the space available and therefore the size of penetrating species influences the absorption behavior. Diffusion into the living tissue, however, is in favor of polar molecules and objects restricting the invasion of too lipophilic compounds. As a consequence only substances with partition coefficients between 1 and 3 are well suited for skin absorption (Schneider et al.).

Dermocosmetic based polymeric nanoparticles provide broad opportunities for preventing aging and skin care, as well as for dermatological affections such as psoriasis, acne, eczema, skin mycosis, and inflammations (Papakostas et al., 2011).

Skin diffusion of nanoparticles. The penetration of polymeric nanoparticles into the skin as a carrier of bioactive compounds has been rarely investigated. Studies carried out using confocal laser scanning microscopy (CLSM) to analyze the distribution of fluorescent polystyrene nanoparticles with a diameter of 20 and $200 \mathrm{~nm}$ in porcine skin demonstrated the preferential accumulation of the particles in the follicular openings, and particularly the particle size of $20 \mathrm{~nm}$. Moreover, the quantity nanoparticles accumulated in the skin was in a time-dependent manner (Alvarez-Roman et al., 2004a). In another study of crosssectional images obtained by CLSM from porcine ear, skin treated with Nile Red-loaded poly(e-caprolactone) (PLC) nanoparticles $(250 \mathrm{~nm})$, Nile Red solution in propylene glycol, and Nile red saturated solution in propylene glycol showed a deeper fluorescence distribution in the skin of Nile Red from nanoparticles samples reaching a thickness of 60 mm (Alvarez-Roman et al., 2004b).

A comparative study between hollow polymeric nanocapsules particle size $178 \mathrm{~nm}$ and zeta potential $-11 \mathrm{mV}$, with lipid-core polymeric nanocapsules particle size 180 $\mathrm{nm}$ and zeta potential $-9 \mathrm{mV}$ showed a deeper penetration of hollow polymeric nanocapsules (dermis vs. outermost layers of the skin respectively) suggesting that the mechanical flexibility of nanoparticles is a critical factor for the skin 

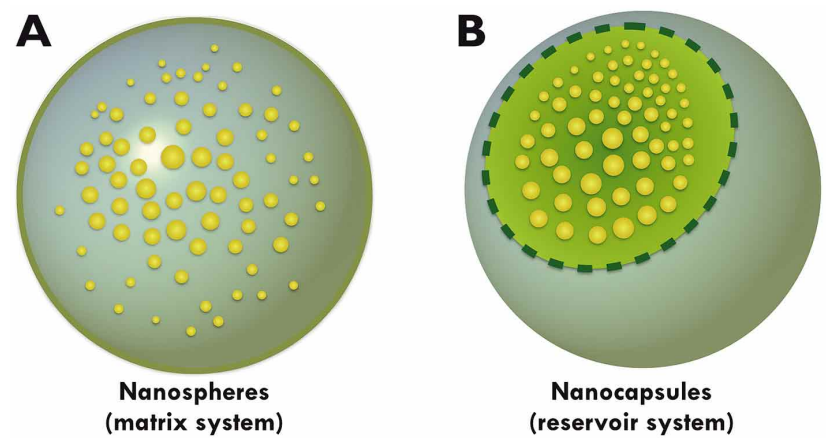

Fig. 1. Scheme of polymeric nanostructures (A) nanospheres (matrix system) and (B) nanocapsules (reservoir system) typically used in dermocosmetics.

penetration (de Brum et al., 2015). Figure 2, shows a scheme of the penetration of polymeric nanoparticles in the skin.

The transepidermal drug delivery also was investigated with polylactic acid (PLA) nanoparticles loaded with Nile Red $(228 \mathrm{~nm})$ and coumarin-6 $(365 \mathrm{~nm})$ in human skin explants obtained from healthy volunteers undergoing plastic surgery. The obtained results demonstrate in both cases that $-50 \%$ of the particles penetrated deep in the vellus hair follicles, suggesting that when the nanoparticles are in contact with the skin surface, they suffer destabilization and significant release of incorporated dye (Rancan et al., 2009). Those results later were confirmed using the same PLA nanoparticles loaded with the hydrophilic fluorochrome 4Di- 2-Asp, and with the lipophilic fluorochrome Bodipy 630/ 650. In this study, the authors also conclude that diffusion kinetics depended on the lipophilicity of the dye (bioactive compound), and the stability and release properties of the particles could be modulated incorporating excipients with different degree of lipophilicity (Rancan et al., 2012).

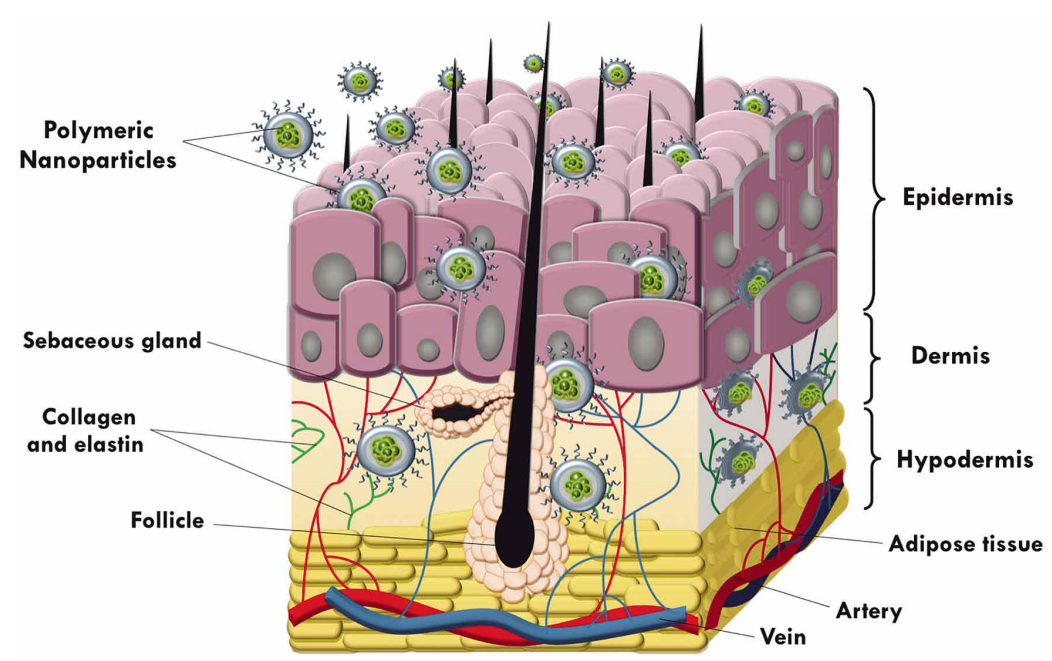

Fig. 2. Schematic description of the layers of the skin (epidermis, dermis, and hypodermis), and the penetration of nanoparticles into its diverse structures.
Dermocosmetic Applications. The main advantages using polymeric nanoparticles in drug delivery and dermocosmetics involve the creation of strong platforms that allow to reduce the cytotoxicity, overcome several biological barriers and provide a sustained and targeted release of bioactive molecules. The use of sunscreen in the population is an essential self-care carefulness since the adverse effects of ultraviolet radiation (UVR) on the skin. The use of titanium dioxide, and zinc oxide nanoparticles in sunscreen current is highly accepted, however, the risk of generation of free radicals, and subsequent side effects to promote the study of novel biomaterials for sunscreen. A recent study developed a set of sunscreen creams based on morin-loaded PLGA nanoparticles, which combined with titanium and zinc dioxide nanoparticles exhibited high deposit and diffusion in the skin with excellent SPF (Sun Protection factor) values and effective antioxidant effect. This investigation based in PLGA nanoparticles loaded with morin, a natural polyphenol with photoprotection and antioxidants properties, promise a high impact of polymeric nanoparticles in sunscreen creams development (Shetty et al., 2015).

Vitamin $\mathrm{K} 1$ is an active antioxidant used in dermatology with recognized anti-age effects. Studies performed with Vitamin K1-loaded polymeric nanocapsules prepared from PLC (diameter of $211 \pm 2 \mathrm{~nm}$, and zeta potential of $-14.9 \pm 0.6 \mathrm{mV}$ ) showed significant skin permeation into of dermis. This place is where Vitamin K1 exhibits its effects in the treatment of dark circles, telangiectasia and bruising of the skin (da Silva et al., 2013). These biomaterials and nanotechnology could be applied in wound healing with treatment based on Ulmo honey (E. cordifolia) supplemented with ascorbic acid (Schencke et al., 2013).

Skin inflammation is a typical manifestation of several disorders of the skin arisen by different factors such as skin exposure to the sun, irritant chemicals, heat or insect bites that affect the health, and aesthetic of the skin. In this context, nanoparticles synthesized from ethyl cellulose and betamethasone in a range of size between 50 to $1000 \mathrm{~nm}$ was studied in an experimental dithranol-induced dermatitis inflammation model in mice ears. The analysis of skin penetration of particles was size-dependent manner and were smaller nanoparticles (100 and $50 \mathrm{~nm}$ ) diffused better into the hair follicle. Also, those particles were highly accumulated in the sebaceous glands. The anti-inflammatory effect was found in the treatment with both particle sizes BetaNP1000 (1000 nm), and 
BetaNP100 (100 nm), however, the therapeutic response was much higher with the BetaNP100, due to its high diffusion within the stratum corneum (Abdel-Mottaleb et al., 2012).

The use of hair follicle as selective targeting tool for dermatotherapy represents also a remarkable opportunity for the developments of novel strategies for dermocosmetics, and immunotherapy (Mittal et al., 2013; Vogt et al., 2005). The diffusion of polymeric nanoparticles into the hair follicle has been well described, as well as, its storage into the follicle even for ten days (Lademann et al., 2007). Recent strategies of chitosan nanoparticles encapsulating the drug minoxidil (MXS-NP) for the treatment of alopecia have showed promising results. MXS-NP increased in a two-fold the concentration of drug into the hair follicles after six hours of treatment in comparison to the control solution (Matos et al., 2015).

Transcutaneous immunization is another concept that refers to the needle-free application of vaccines across the skin. The literature has described that the skin holds an abundance of professional antigen-presenting cells such as dendritic cells, and Langerhans cells. Therefore, the use of polymeric nanoparticles could provide novel strategies for transfollicular delivery of antigens. A recent study using PLGA and chitosan-coated PLGA nanoparticles loaded with ovalbumin showed a high follicular uptake of nanoparticles. Also, the study of activation of dendritic cells showed a positive proliferation of antigen-specific CD8+ and CD4+ $\mathrm{T}$ cells supporting the maintenance of the integrity of the antigen during the process of synthesis of nanoparticles and the efficacy of cell stimulation. In this context, the transcutaneous immunization represents a potent concept for patients with an impaired immune system or the elderly (Mittal et al.).

\section{Concluding remarks}

The use of polymeric nanoparticles in cosmetic dermatology offers a range of new opportunities for both maintenance of the health, and physiological properties of the skin, as well as creating better products cosmetics (e.g. incorporating metal nanoparticles copper or gold). Furthermore, The nanoparticles allow to improve the physicochemical properties of the classic cream emulsions and to enhance the penetration of the bioactive compounds until deep layers of the skin. The next generation of particles as nanocarriers could offer an arsenal of cargo molecules that allow keeping the hydration of the skin, elasticity, cellular matrix equilibrium, and other functions related with the beauty. Hair follicular delivery based polymeric nanoparticles represents a powerful non-invasive route of administration for skin maintenance and systemic stimulation for the development of novel vaccines.

\section{ACKNOWLEDGEMENTS}

C.V. acknowledges the support from the Center for the Development of Nanoscience and Nanotechnology (CEDENNA), Grant FB0807, CONICYT; K.Z. acknowledges the financial support of the Doctoral Scholarship of CONICYT, Government of Chile.

BAHAMONDE-NORAMBUENA, D.; MOLINA-PEREIRA, A.; CANTIN, M.; MUÑOZ, M.; ZEPEDA, K. \& VILOS, C. Nanopartículas poliméricas en dermocosmética. Int. J. Morphol., 33(4):1563-1568, 2015.

RESUMEN: Los recientes avances en el campo de los biomateriales y la nanotecnología han permitido el desarrollo de nanopartículas avanzadas para aplicaciones biomédicas. A pesar de que un gran número de nanoestructuras tales como liposomas, nanocápsulas lípidosólidas, nanopartículas poliméricas y lípido-polímero híbridas han sido estudiadas como vehículos para la administración de fármacos en diferentes patologías con notables resultados prometedores, el uso de nanopartículas poliméricas en dermocosmética todavía no ha sido ampliamente explorado. La evolución de la cosmética en el cuidado de la piel y la dermatología nos enfrentan a nuevos retos tecnológicos. Además, el aumento de los conocimientos sobre la fisiología de la piel normal y los avances en la nanotecnología proporcionan un entorno atractivo para la creación de formulaciones dermocosméticas innovadoras. En este trabajo se discute el estado del arte de las nanopartículas poliméricas desarrolladas para dermocosmética, sus mecanismos de acción y la difusión en la piel.

PALABRAS CLAVE: Nanotecnología; Nanopartículas poliméricas; Morfología de la piel; Cosméticos; Dermocosmética.

\section{REFERENCES}

Abdel-Mottaleb, M. M.; Moulari, B.; Beduneau, A.; Pellequer, Y. \& Lamprecht, A. Nanoparticles enhance therapeutic outcome in inflamed skin therapy. Eur. J. Pharm. Biopharm., 82(1):1517, 2012.
Alvarez-Román, R.; Naik, A.; Kalia, Y. N.; Guy, R. H. \& Fessi, H. Skin penetration and distribution of polymeric nanoparticles. J. Control Release, 99(1):53-62, 2004a. 
Alvarez-Román, R.; Naik, A.; Kalia, Y. N.; Guy, R. H. \& Fessi, H. Enhancement of topical delivery from biodegradable nanoparticles. Pharm. Res., 21(10):1818-25, $2004 \mathrm{~b}$.

Arda, O.; Göksügür, N. \& Tüzün, Y. Basic histological structure and functions of facial skin. Clin. Dermatol., 32(1):3-13, 2014.

Barua, S. \& Mitragotri, S. Challenges associated with penetration of nanoparticles across cell and tissue barriers: A review of current status and future prospects. Nano Today, 9(2):22343,2014

Bouwstra, J. A. \& Honeywell-Nguyen, P. L. Skin structure and mode of action of vesicles. Adv. Drug Deliv. Rev., 54 (Suppl. 1):S41-55, 2002.

Cantín, M.; Miranda, P.; Suazo Galdames, I.; Zavando, D.; Arenas, P.; Velásquez, L. \& Vilos, C. In vivo biocompatibility of the PLGA microparticles in parotid gland. Int. J. Clin. Exp. Pathol., 6(11):2412-8, 2013.

Choi, W. I.; Kamaly, N.; Riol-Blanco, L.; Lee, I. H.; Wu, J.; Swami, A.; Vilos, C.; Yameen, B.; Yu, M.; Shi, J.; Tabas, I.; von Andrian, U. H.; Jon, S. \& Farokhzad, O. C. A solventfree thermosponge nanoparticle platform for efficient delivery of labile proteins. Nano Lett., 14(11):6449-55, 2014.

da Silva, A. L.; Contri, R. V.; Jornada, D. S.; Pohlmann, A. R. \& Guterres, S. S. Vitamin K1-loaded lipid-core nanocapsules: physicochemical characterization and in vitro skin permeation. Skin Res. Technol., 19(1):e223-30, 2013.

de Brum, T. L.; Fiel, L. A.; Contri, R. V.; Guterres, S. S. \& Pohlmann, A. R. Polymeric nanocapsules and lipid-core nanocapsules have diverse skin penetration. J. Nanosci. Nanotechnol., 15(1):773-80, 2015.

Dreno, B.; Araviiskaia, E.; Berardesca, E.; Bieber, T.; Hawk, J.; Sanchez-Viera, M. \& Wolkenstein, P. The science of dermocosmetics and its role in dermatology. J. Eur. Acad. Dermatol. Venereol., 28(11):1409-17, 2014.

Fredman, G.; Kamaly, N.; Spolitu, S.; Milton, J.; Ghorpade, D.; Chiasson, R.; Kuriakose, G.; Perretti, M.; Farokhzad, O. \& Tabas, I. Targeted nanoparticles containing the proresolving peptide Ac2-26 protect against advanced atherosclerosis in hypercholesterolemic mice. Sci. Transl. Med., 7(275):275ra220, 2015.

Freitag, F. M. \& Cestari, T. F. What causes dark circles under the eyes? J. Cosmet. Dermatol., 6(3):211-5, 2007.

Guo, W.; Tao, J.; Yang, C.; Song, C.; Geng, W.; Li, Q.; Wang, Y.; Kong, M. \& Wang, S. Introduction of environmentally degradable parameters to evaluate the biodegradability of biodegradable polymers. PLoS One, 7(5):e38341, 2012.

Guterres, S. S.; Alves, M. P. \& Pohlmann, A. R. Polymeric nanoparticles, nanospheres and nanocapsules, for cutaneous applications. Drug Target Insights, 2:147-57, 2007.

Kamaly, N.; Xiao, Z.; Valencia, P. M.; Radovic-Moreno, A. F. \& Farokhzad, O. C. Targeted polymeric therapeutic nanoparticles: design, development and clinical translation. Chem. Soc. Rev., 41(7):2971-3010, 2012.

Kim, G.; Rho, Y.; Park, S.; Kim, H.; Son, S.; Kim, H.; Kim, I. J.; Kim, J. R.; Kim, W. J. \& Ree, M. The biocompatibility of self-assembled brush polymers bearing glycine derivatives. Biomaterials, 31(14):3816-26, 2010.

Lademann, J.; Richter, H.; Teichmann, A.; Otberg, N.; BlumePeytavi, U.; Luengo, J.; Weiss, B.; Schaefer, U. F.; Lehr, C. M.; Wepf, R. \& Sterry, W. Nanoparticles--an efficient carrier for drug delivery into the hair follicles. Eur. J. Pharm. Biopharm., 66(2):159-64, 2007.

Matos, B. N.; Reis, T. A.; Gratieri, T. \& Gelfuso, G. M. Chitosan nanoparticles for targeting and sustaining minoxidil sulphate delivery to hair follicles. Int. J. Biol. Macromol., 75:225-9, 2015.

Mittal, A.; Raber, A. S.; Schaefer, U. F.; Weissmann, S.; Ebensen, T.; Schulze, K.; Guzmán, C. A.; Lehr, C. M. \& Hansen, S. Non-invasive delivery of nanoparticles to hair follicles: a perspective for transcutaneous immunization. Vaccine, 31(34):3442-51, 2013.

Morganti, P. Use and potential of nanotechnology in cosmetic dermatology. Clin. Cosmet. Investig. Dermatol., 3:5-13, 2010 .

Papakostas, D.; Rancan, F.; Sterry, W.; Blume-Peytavi, U. \& Vogt, A. Nanoparticles in dermatology. Arch. Dermatol. Res., 303(8):533-50, 2011.

Rancan, F.; Papakostas, D.; Hadam, S.; Hackbarth, S.; Delair, T.; Primard, C.; Verrier, B.; Sterry, W.; Blume-Peytavi, U. \& Vogt, A. Investigation of polylactic acid (PLA) nanoparticles as drug delivery systems for local dermatotherapy. Pharm. Res., 26(8):2027-36, 2009.

Rancan, F.; Todorova, A.; Hadam, S.; Papakostas, D.; Luciani, E.; Graf, C.; Gernert, U.; Rühl, E.; Verrier, B.; Sterry, W.; Blume-Peytavi, U. \& Vogt, A. Stability of polylactic acid particles and release of fluorochromes upon topical application on human skin explants. Eur. J. Pharm. Biopharm., 80(1):76-84, 2012.

Schencke, C.; Salvo, J.; Vasconcellos, A. \& del Sol, M. Comparative Study of Healing in Burns Treatment Based on Ulmo Honey (Eucryphia cordifolia) and Oral Vitamin C in Guinea Pig (Cavia porcellus) versus Hydrogel. Int. J. Morphol., 31(3):839-44, 2013.

Shetty, P. K.; Venuvanka, V.; Jagani, H. V.; Chethan, G. H.; Ligade, V. S.; Musmade, P. B.; Nayak, U. Y.; Reddy, M. S.; 
Kalthur, G.; Udupa, N.; Rao, C. M. \& Mutalik, S. Development and evaluation of sunscreen creams containing morin-encapsulated nanoparticles for enhanced UV radiation protection and antioxidant activity. Int. J. Nanomedicine, 10:6477-91, 2015.

Schneider, M.; Stracke, F.; Hansen, S. \& Schaefer, U. F. Nanoparticles and their interactions with the dermal barrier. Dermatoendocrinol., 1(4):197-206, 2009.

Thouand, G. Biodegradability assessments of organic substances and polymers. Environ. Sci. Pollut. Res. Int., 21(16):9443-4, 2014.

Vilos, C. Nanotechnology in preclinical and clinical drug development. Int. J. Med. Surg. Sci., 1(1):73-93, 2014.

Vilos, C.; Constandil, L.; Herrera, N.; Solar, P.; Escobar-Fica, J. \& Velásquez, L. A. Ceftiofur-loaded PHBV microparticles: A potential formulation for a long-acting antibiotic to treat animal infections. Electron. J. Biotechnol., 15(4):13p., 2012.

Vilos, C.; Gutiérrez, M.; Escobar, R. A.; Morales, F.; Denardin, J. C.; Velásquez, L. \& Altbir, D. Superparamagnetic Poly (3hydroxybutyrate-co-3 hydroxyvalerate) (PHBV) nanoparticles for biomedical applications. Electron. J. Biotechnol., 16(5):10p., 2013.

Vilos, C.; Constandil, L.; Rodas, P. I.; Cantin, M.; Zepeda, K.; Herrera, N. \& Velasquez, L. A. Evaluation of ceftiofur-PHBV microparticles in rats. Drug Des. Devel. Ther., 8:651-66, 2014.

Vilos C.; Velasquez, L. A.; Rodas, P. I.; Zepeda, K.; Bong, S. J.; Herrera, N.; Cantin, M.; Simon, F. \& Constandil, L. Preclinical Development and In Vivo Efficacy of Ceftiofur-PLGA Microparticles. PLoS One, 10(4):e0123335, 2015.

Vilos, C. \& Velasquez, L. A. Therapeutic strategies based on polymeric microparticles. J. Biomed. Biotechnol., 2012:672760, 2012.

Vogt, A.; Mandt, N.; Lademann, J.; Schaefer, H. \& Blume-Peytavi, U. Follicular targeting--a promising tool in selective dermatotherapy. J. Investig. Dermatol. Symp. Proc., 10(3):252$5,2005$.

Xu, X.; Ho, W.; Zhang, X.; Bertrand, N. \& Farokhzad, O. Cancer nanomedicine: from targeted delivery to combination therapy. Trends Mol. Med., 21(4):223-32, 2015.
Correspondence to:

Dr. Cristian Vilos

Universidad Andres Bello

Faculty of Medicine

Center for Integrative Medicine and Innovative Science (CIMIS)

www.vilosgroup.com

Echaurren 183, 8370071

Santiago

CHILE

Phone: +562 (2) 7703902

Email: cristian.vilos@unab.cl

Received: 06-06-2015

Accepted: 28-09-2015 